\title{
Relationship Between Insulin Resistance and Vitamin B12 Deficiency in Obese Children
}

\author{
Fatma Dursun 1, (1) Nelgin Gerenli ${ }^{2}$
}

${ }^{1}$ Department of Paediatric Endocrinology, University of Health Sciences, Umraniye Training and Research Hospital, Istanbul, Turkey

${ }^{2}$ Department of Paediatric Gastroenterology, University of Health Sciences, Umraniye Training and Research Hospital, Istanbul, Turkey

\begin{abstract}
Introduction: The increase in the incidence of obesity leads to an increase in the frequency of obesity-related complications such as insulin resistance (IR), hypertension, and hyperlipidemia. This study aimed to examine the relationship between B12 levels and IR in obese patients.

Methods: A total of 110 children aged 10-16 years who presented to pediatric endocrinology outpatient clinic for obesity were enrolled. The homeostasis model of assessment-insulin resistance (HOMA-IR) made the diagnosis of IR. The patients who had previously received B12 and metformin treatment were excluded from the study. The vitamin B12 levels between patients with and without IR were compared. The correlation between B12 levels and IR was evaluated.

Results: When patients with IR were compared with those without IR, a statistically significant difference was observed in serum B12 levels ( $p=0.019)$. A strong negative correlation was observed between vitamin B12 levels and IR $(r=-0.259, p=0.008)$.

Discussion and Conclusion: We found that vitamin B12 levels were significantly lower in obese children with IR. Metformin used for IR is known to have lowered the absorption of vitamin B12. In addition to screening of IR and other co-morbidities in obesity, the lack of vitamin B12 should also be investigated. If deficient, vitamin B12 should be replaced before starting metformin treatment. Further studies are needed to examine the effect of vitamin B12 deficiency on the pathogenesis of IR. Keywords: Insulin resistance; obesity; vitamin B12 deficiency.
\end{abstract}

$\mathrm{V}$ tamin B12, found in many animal foods, is an essential vitamin. It is involved in DNA synthesis, hematopoiesis, and neurological functions. Its deficiency can be seen with metformin treatment, obesity, insulin resistance, and type 2 diabetes, apart from inadequate uptake and malabsorption ${ }^{[1-3]}$.

Obesity has become a global health problem. It is often accompanied by many co-morbidities such as insulin resistance (IR), type 2 diabetes mellitus, hypertension, dyslipidemia, non-alcoholic fatty liver disease, and cardiovascular disease. These co-morbidities determine life expectancy in obesity.

Recent studies have shown that obese children have lower levels of vitamin B12 ${ }^{[4,5]}$. Macfarlane et al. ${ }^{[5]}$ showed that B12 deficiency was higher in children aged 6-19 years compared to that in children with normal weight. However, this relationship was not well defined. Only a smaller number of studies concerning vitamin B12 levels have been performed in obese children with ID or prediabetes ${ }^{[1]}$. Since metformin is frequently used in obese children with ID, and this leads

Correspondence (İletişim): Fatma Dursun, M.D. Umraniye Egitim ve Arastirma Hastanesi, Saglik Bilimleri Universitesi, Cocuk Endokrinolojisi Anabilim Dali, Istanbul, Turkey

Phone (Telefon): +90 5052671403 E-mail (E-posta): fatmadursun54@yahoo.com

Submitted Date (Başvuru Tarihi): 02.03.2018 Accepted Date (Kabul Tarihi): 18.05.2018

Copyright 2019 Haydarpaşa Numune Medical Journal

This is an open access article under the CC BY-NC license (http://creativecommons.org/licenses/by-nc/4.0/). 
to vitamin B12 deficiency, assessment of B12 levels in these children is very important.n this study, vitamin B12 levels were evaluated in obese children with and without IR.

\section{Materials and Methods}

A total of 110 patients with body mass indexes (BMI) $>95$ percentile who were admitted to the pediatric endocrinology outpatient clinic with the diagnosis of obesity were enrolled in the study. Obese patients who had previously received $\mathrm{B} 12$ treatment or metformin for $\mathrm{IR}$, multivitamin preparations, and had other chronic diseases, or were receiving medications for their chronic diseases were excluded from the study. Ethics committee approval was obtained from the ethics committee of our hospital (approved number: 21.02.2018/5331).

Patients were divided into two groups: Group 1 consisted of patients without insulin resistance, and Group 2 consisted of patients with insulin resistance. Obesity was defined as having $\mathrm{BMI}$ above 95 percentile ${ }^{[6]}$. BMI was calculated by the formula: weight $(\mathrm{kg}) /$ height $^{2}\left(\mathrm{~m}^{2}\right)$, and BMI reference percentiles prepared for Turkish children were used ${ }^{[7]}$. All blood samples were drawn in the morning after 12 hours of fasting. The reference range of the device used to determine vitamin B12 deficiency was calculated, and the values below $187 \mathrm{pg} / \mathrm{ml}$ were accepted as vitamin B12 deficiency.

In obese children, homeostasis model for assessment of insulin resistance (HOMA-IR) was used to calculate IR. HOMA-IR was calculated as follows: fasting blood glucose $(\mathrm{mg} / \mathrm{dl}) \times$ fasting insulin $(\mathrm{mU} / \mathrm{mL}) / 405{ }^{[8]}$. The diagnosis of IR was defined as HOMA-IR $>2.6$ for prepubertal girls, $>2.6 \%$ in males, $>3.8$ in pubertal females, and $>5.2$ in pubertal males ${ }^{[9]}$.

Laboratory tests were used to evaluate the following parameters: alanine aminotransferase (ALT), aspartate aminotransferase (AST), triglyceride (TG), total cholesterol (TC), low-density lipoprotein (LDL), high-density lipoprotein (HDL), complete blood count, fasting blood glucose (FBG), insulin, and vitamin B12. FBG, ALT, and AST levels were measured using the Abbott i8000 device and Abbott kits in our central laboratory. FBG levels were measured by hexokinase method, and ALT and AST were measured by enzymatic method. The insulin levels were studied using the Abbott i16000 device and the chemiluminescent microparticle immunoassay (CMIA) method.

Vitamin B12 was measured with the Abbott device and chemiluminescence immunoassay method.

\section{Statistical Analysis}

When evaluating the findings obtained in this study, IBM SPSS Statistics 22 for statistical analysis (SPSS IBM, Turkey) program was used. The fit of the parameters to normal distribution was evaluated by the Shapiro-Wilks test. To evaluate the study data, aside from descriptive statistical methods (mean, standard deviation), Student's t-test was used for intergroup comparison of quantitative data of normally distributed parameters. The Mann-Whitney $U$ test was used for intergroup comparisons of parameters with non-normal distribution. Pearson correlation test was used for the correlation analysis of the normally distributed parameters. Significance was evaluated at $p<0.05$.

\section{Results}

Of the 110 patients included in this study, $55.5 \%(n=61)$ were female, and $44.5 \%(n=49)$ were male. Insulin resistance was detected in 35 (31.8\%) patients. The mean age of Group 2 was significantly higher $(p<0.05)$. The mean BMI was significantly higher in Group $2(p<0.05)$. Demographic and laboratory results of the patients are given in Tables 1 and 2 .

Vitamin B12 levels were significantly lower in Group 2 with IR $(p=0.019)$. The ALT levels were significantly higher in Group $2(p<0.01)$. The triglyceride levels were statistically significantly higher in patients with IR $(p<0.05)$; but no significant difference was found between AST, HDL, TC, and uric acid levels in both groups. The LDL cholesterol levels were significantly higher in Group $1(p=0.0)$.

Vitamin B12 levels were below $187 \mathrm{pg} / \mathrm{ml}$ in 21 (19\%) patients. While vitamin B12 levels were low in 12 of $75(75 \%)$ patients without IR, vitamin B12 levels were lower in 9 of 35 (25.7\%) patients with IR. BMI was found to be $32.58 \pm 5.09 \mathrm{~kg} /$ $\mathrm{m}^{2}$ in patients with low vitamin B12 levels and 30.61 \pm 9.52 $\mathrm{kg} / \mathrm{m}^{2}$ in patients with normal vitamin B12 levels.

A negative correlation was observed between vitamin $B 12$ levels and HOMA-IR ( $p=0.008, r=-0.259)$. No significant relationship was observed between BMl and vitamin B12 levels $(p=0.075, r=-0.33)$.

Table 1. Demographic characteristics of the patients

\begin{tabular}{|c|c|c|c|c|}
\hline & $\begin{array}{c}\text { Group } 1 \\
\text { Mean } \pm \text { SD }\end{array}$ & $\begin{array}{c}\text { Group } 2 \\
\text { Mean士SD }\end{array}$ & $\begin{array}{l}\text { All patients } \\
\text { Mean } \pm \text { SD }\end{array}$ & $\mathbf{p}$ \\
\hline Age (years) & $11.8 \pm 2.7$ & $12.9 \pm 1.8$ & $12.19 \pm 2.58$ & 0.012 \\
\hline Female, n (\%) & $42(38.2)$ & $19(17.3)$ & $61(55.5)$ & 0.343 \\
\hline Male, n (\%) & $33(30)$ & $16(14.5)$ & $49(44.5)$ & \\
\hline Prepubertal, n (\%) & $14(45.1)$ & $17(54.8)$ & $31(28.2)$ & 0.240 \\
\hline Pubertal, n (\%) & $61(77.2)$ & $18(22.7)$ & $79(71.8)$ & \\
\hline BMI $\left(\mathrm{kg} / \mathrm{m}^{2}\right)$ & $30.1 \pm 10$ & $33.1 \pm 4.9$ & $30.92 \pm 8.88$ & 0.04 \\
\hline
\end{tabular}

BMI: Body mass index; SD: standard deviation; $\mathrm{p}<0.05$. 
Table 2. Laboratory test results of the patients with and without insulin resistance

\begin{tabular}{|c|c|c|c|c|}
\hline & $\begin{array}{c}\text { Group } 1 \\
\text { Mean } \pm \text { SD }\end{array}$ & $\begin{array}{c}\text { Group } 2 \\
\text { Mean } \pm \text { SD }\end{array}$ & $\begin{array}{c}\text { Total } \\
\text { Mean } \pm \text { SD }\end{array}$ & $\mathbf{p}$ \\
\hline $\mathrm{AST}^{1}{ }_{\text {(median) }}$ & $26.2 \pm 31.5(49)$ & $28.16 \pm 15.7(63)$ & $26.86 \pm 27.65(21)$ & $0.031^{* *}$ \\
\hline $\mathrm{ALT}^{1}{ }_{\text {(median) }}$ & $31.01 \pm 53.8(46)$ & $43.13 \pm 35.9(70)$ & $34.48 \pm 49.28(22)$ & $0.00^{* *}$ \\
\hline Triglyceride & $119.65 \pm 54.21$ & $146.33 \pm 63.96$ & $128.01 \pm 58.37$ & $0.04^{*}$ \\
\hline HDL & $41.45 \pm 10.11$ & $41.06 \pm 7.26$ & $41.0 \pm 9.28$ & 0.38 \\
\hline LDL & $110.6 \pm 29.7$ & $98.3 \pm 20.6$ & $106.71 \pm 27.55$ & $0.01 *$ \\
\hline Cholesterol & $177.5 \pm 33.4$ & $166.1 \pm 25$ & $173.82 \pm 31.29$ & 0.06 \\
\hline Uric acid & $5.46 \pm 1.27$ & $5.70 \pm 2.24$ & $5.54 \pm 1.63$ & 0.67 \\
\hline B12 & $321.69 \pm 150.8$ & $265.14 \pm 94.8$ & $319.65 \pm 145.21$ & $0.019^{*}$ \\
\hline HOMA-IR & $3.04 \pm 1.15$ & $6.66 \pm 2.43$ & $4.22 \pm 2.31$ & $0.00^{*}$ \\
\hline $\mathrm{Hb}(\mathrm{g} / \mathrm{dl})$ & $12.76 \pm 0.91$ & $13.31 \pm 1.22$ & $12.91 \pm 1.02$ & 0.06 \\
\hline Htc (\%) & $38.91 \pm 2.66$ & $40.15 \pm 3.98$ & $39.24 \pm 3.09$ & 0.18 \\
\hline MCV & $79.77 \pm 10.6$ & $78.9 \pm 10.94$ & $79.55 \pm 10.66$ & 0.76 \\
\hline
\end{tabular}

${ }^{1}$ Mann-Whitney U test; ${ }^{*} \mathrm{p}<0.05 ;{ }^{* *} \mathrm{p}<0.01$.

\section{Discussion}

In this study, we have shown that B12 deficiency is more frequent in obese children with IR than in those without IR. Few studies in the literature show the relationship between vitamin $\mathrm{B} 12$ and insulin resistance in obese children ${ }^{[1]}$. In a study by Ho et al., ${ }^{[1]} \mathrm{B} 12$ levels were found to be low or borderline normal in one-third of obese adolescents with insulin resistance. In our study, vitamin B12 levels were significantly lower in Group 2 with IR ( $\mathrm{p}=0.019)$. A negative correlation was observed between $B 12$ and IR $(p=0.008, r=-0.259)$.

There are few studies on vitamin B12 levels in obese children, and vitamin B12 deficiency has been reported to be around $10 \%-20 \%[4,5,10]$. In our study, vitamin B12 deficiency was found in $19 \%$ of obese children. This rate was consistent with that in the literature ${ }^{[5]}$.

There is no consensus on the diagnosis of vitamin B12 deficiency. The most acceptable and cost-effective method is measurement of serum B12 levels ${ }^{[11]}$, Since it is not a universally accepted threshold value, the threshold value for the age range of the method studied in our hospital was used. The threshold value of our hospital device was 187 $\mathrm{pg} / \mathrm{ml}$, and below the value of $187 \mathrm{pg} / \mathrm{ml}$ were defined as vitamin B12 deficiency.

However, methylmalonic acid and homocysteine levels that are more sensitive for B12 deficiency were not evaluated in this study. Another weak point of our study was the lack of a control group in which vitamin B12 levels were measured in children with normal weight.

In a recent study published by Li et al. ${ }^{[12]}$, the way vitamin B12 deficiency affects insulin resistance was described as follows: B12 deficiency leads to insufficiency in the syn- thesis of methionine by inducing leakage of cellular folate, which increases the stress in the endoplasmic reticulum by causing deficiency of oxidation of free fatty acids.

Because B12 is a cofactor in the conversion of methylmalonic acid to succinylcholine, methylmalonic acid accumulates in B12 deficiency, and causes lipogenesis and insulin resistance ${ }^{[12]}$. Hence, in obese children, lower vitamin B12 levels are seen to no less a degree. We found that serum B12 levels were lower in patients with IR. Metformin used with indication of $I R$ also decreases the absorption of vitamin B12. It is important to consider and treat B12 before treatment. In obese patients, besides vitamin $D$ and other concomitant diseases, vitamin B12 deficiency should be investigated. Further studies are needed on the effect of vitamin B12 deficiency on the pathogenesis of IR.

Ethics Committee Approval: Ethics committee approval was obtained from the ethics committee of our hospital (approved number: 21.02.2018/5332).

Peer-review: Externally peer-reviewed.

Authorship Contributions: Concept: F.D.; Design: F.D.; Data Collection or Processing: F.D., N.G.; Analysis or Interpretation: F.D., N.G.; Literature Search: F.D.; Writing: F.D:, N.G.

Conflict of Interest: None declared.

Financial Disclosure: The authors declared that this study received no financial support.

\section{References}

1. Ho M, Halim JH, Gow ML, El-Haddad N, Marzulli T, Baur LA, et al. Vitamin B12 in obese adolescents with clinical features of insülin resistance. Nutrients 2014;6:5611-8. [CrossRef]

2. Stabler SP. Vitamin B12 deficiency. N Eng J Med 2013;368:149-60. 
3. Reinstatler L, Qi YP, Williamson RS, Garn JV, Oakley GP. Association of biochemical B12 deficiency with metformin therapy and vitamin B12 supplements: The national health and nutrition examination survey. Diabetes Care 2012;35:327-33.

4. Pinhas-Hamiel O, Doron PN, Reichman B, Nitzan KD, Shalitin S, Geva-Lerner L. Obese children and adolescents: a risk group for low vitamin B12 concentration. Arch Pediatr Adolesc Med 2006;160:933-6. [CrossRef]

5. MacFarlane AJ, Greene-Finestone LS, Shi Y. Vitamin B12 and homocysteine status in a folate-replete population: Results from the canadian health measures survey. Am J Clin Nutr 2011;94:1079-87. [CrossRef]

6. Physical status: the use and interpretation of antropometry. Report of a WHO Expert Committee. World Health Organ Tech Rep Ser 1995;854:1-452.

7. Bundak R, Furman A, Gunoz H, Darendeliler F, Bas F, Neyzi O. Body mass index references for Turkish children. Acta Paediatr 2006;95:194-8. [CrossRef]
8. Matthews DR, Hosker JP, Rudenski AS, Naylor BA, Treacher DF. Homeostasis model assessment: insulin resistance and betacell function from fasting plasma glucose and insulin concentrations in man. Diabetologia 1985;28:412-9. [CrossRef]

9. Kurtoğlu S, Hatipoğlu N, Mazıcıoğlu M, Kendirci M, Keskin M, Kondolot $M$. Insulin resistance in obese children and adolescents: HOMA-IR cut-off levels in the prepubertal and pubertal periods. J Clin Res Pediatr Endocrinol 2010;2:100-6. [CrossRef]

10. Food and nutrition guidelines for healthy adolescents. New Zealand Ministry of Health. Available at: http://www.moh. govt.nz. Accessed March 1, 2019.

11. Willis CD, Metz MP, Hiller JE, Elshaug AG. Vitamin B12 and folate tests: The ongoing need to determine appropriate use and public funding. Med J Aust 2013;198:586-8. [CrossRef]

12. Li Z, Gueant-Rodriguez RM, Quilliot D, Sirveaux MA, Meyre D, Gueant $\mathrm{J}$, et al. Folate and vitamin B12 status is associated with insulin resistance and metabolic syndrome in morbid obesity. Clin Nutr 2017;37:1700-6. [CrossRef] 